\title{
COMBATE À CORRUPÇÃO MARCA UMA NOVA REPÚBLICA EM CONSTRUÇÃO
}

Coluna publicada em 15.11.2016: <https://www.conjur.com.br/2016-nov-15/ contas-vista-combate-corrupcao-marca-republica-construcao $>$

No dia 15 de novembro de 1889, há 127 anos, proclamava-se no Brasil a República Federativa, ${ }^{1}$ cuja data hoje é celebrada como feriado nacional. ${ }^{2}$

A República é uma forma de governo que se opõe, imediatamente, à monarquia e a suas características mais frequentes, como a vitaliciedade, a hereditariedade e a centralidade do monarca, o que pode conduzir à irresponsabilidade. Ainda que com adaptações, um regime republicano se caracteriza pela temporariedade do chefe do governo, por sua eletividade e por sua responsabilização. ${ }^{3}$ Não é à toa que se diz popularmente a expressão "práticas não republicanas", vindas por parte de algum agente público, para relacioná-las com algum indício de corrupção. A ideia de República traz consigo justamente essa transparência que é própria das instituiçōes democráticas.

Mas não é só pela perspectiva formal da existência de controles ao governo que se caracteriza a República. É a participação popular que a qualifica substantivamente como res publica, "coisa pública", o que exige que os chefes de governo e os parlamentos sejam eleitos pelo povo e, portanto, legitimados pelo voto. ${ }^{4} \mathrm{~A}$ soberania popular aproxima as ideias de república e democracia. É por este processo democrático que se elaboram as normas que devem ser observadas e cumpridas por todos, sem distinção.

Decreto 1 , de 15 de novembro de 1889.

2 Lei 662, de 6.4.1949.

3 DALLARI, Dalmo. Elementos de Teoria Geral do Estado. São Paulo: Saraiva, 2005. p. 228-231.

4 SILVA, José Afonso da. Curso de Direito Constitucional Positivo. São Paulo: Malheiros, 2008. p. 103. 
E é nesse contexto de respeito à coisa pública que nos últimos anos a República brasileira está tendo motivos para comemoração e celebração, especialmente em razão do intenso e severo combate à corrupção que se tem observado.

Ainda que se possa lamentar que isto tenha levado à descoberta de que muitos, durante longo tempo, promoveram graves lesões ao patrimônio público, ao erário, à credibilidade das instituições, órgãos e empresas estatais por atos de corrupção, o fato é que o combate tem sido persistente e eficaz, com investigações, processos, condenações e punições, como jamais ocorreu em nossa história.

Já não se pode dizer que, no Brasil, ricos e poderosos não vão para a cadeia, como sempre se falou - e com razão. Estabelecimentos penitenciários como os Complexos da Papuda, em Brasília, e de Pinhais, na região de Curitiba, hoje "hospedam" dezenas de políticos e empresários ricos e poderosos, vários deles já há muito tempo encarcerados.

Os Poderes e as instituições têm se mostrado sólidos, agindo com autonomia e independência, tendo muitos colaborado para esse avanço, incluindo juízes, promotores, policiais, advogados, integrantes da ampla gama de servidores da Justiça como um todo, a imprensa e a população.

O fato é que República e corrupção são incompatíveis em sua essência, e não poderiam estar juntas.

Corrupção é uma palavra cuja definição não é simples nem consensual; trata-se de tema complexo, amplo, multidisciplinar, que pode ser abordado sob diversas perspectivas. Um verdadeiro "jogo de luz e penumbra, que acompanha, com sua carga de ambiguidade, a tênue escala de expressóes existentes no vocabulário brasileiro: cervejinha, gorjeta, jeitinho, caixinha, ajudinha, lubrificar, taxa de urgência, por fora, esquema, rolo, molhar a mão, mamata, negociata, propina, falcatrua, caixa dois etc". ${ }^{5}$ É um termo que "inclui uma enorme diversidade de atos: trapaça, velhacaria, logro, ganho ilícito, desfalque, concussão, falsificação, espólio, fraude, suborno, peculato, extorsão, nepotismo e outros. Isso cria razoável dificuldade para se chegar a uma definição consensual. $\mathrm{O}$ fenômeno pode ser observado numa gradação quase infinita. Vai de pequenos desvios de comportamento à total impunidade do crime organizado, por parte das várias áreas e níveis governamentais". A essência do conceito de corrupção não está na transgressão da lei ou da norma, mas sim "na ameaça à solidariedade social, na inversão da subordinação dos interesses

FERRAZ JÚNIOR, Tercio Sampaio. Corrupção, um mito político. Folha de S.Paulo, 9.11.2015. 
particulares aos interesses gerais, o que fere sentimentos fortes da consciência comum, colocando em risco a coesão social”. ${ }^{6}$

Verdadeiro "câncer" social, uma violência aos Direitos Humanos, 7 a corrupção transformou-se em um dos mais relevantes problemas do mundo contemporâneo, ${ }^{8}$ e tem sido intensamente estudado, destacando-se, dentre outras, a obra de Susan Rose-Ackerman e Bonnie Palifka, ${ }^{9}$ com foco nos aspectos econômicos da corrupção, como os efeitos prejudiciais aos investimentos e ao desenvolvimento da economia. Há diversas análises empíricas que destacam os impactos negativos da corrupção no desenvolvimento humano, na qualidade das instituições governamentais, na realização de negócios no país (que acabam ficando informais), no recebimento de investimento estrangeiro direto, na qualidade da infraestrutura, ${ }^{10}$ no crescimento econômico e da renda per capita, no acesso a serviços públicos, na legitimidade de um governo, no seu rating das agências de classificação de risco e na confiança das pessoas - para citar alguns exemplos.

São bastante conhecidos os efeitos danosos da corrupção sobre a sociedade, a economia e a administração pública.

A corrupção prejudica a livre-concorrência, a partir das vantagens conferidas pelos corruptores, e com isso a competitividade do país, a criação de empregos e o desenvolvimento econômico. $\mathrm{O}$ enfraquecimento da capacidade dos governos de garantir sua própria ordem jurídica, por sua vez, abre espaço para o crime organizado e o tráfico comercial ilícito (aí incluído o tráfico de pessoas, de armas, de drogas, o contrabando, a pirataria etc.). ${ }^{11}$

6 BREI, Zani Andrade. Corrupção: dificuldades para definição e para um consenso. Revista de Administração Pública 30 (1), Rio de Janeiro, jan./fev. 1996, p. 65 e 70.

7 "Daí não termos dúvida em afirmar que a corrupção violenta os Direitos Humanos" (OLIVEIRA, Regis de. Curso de Direito Financeiro. São Paulo: RT, 2013. p. 311).

8 "In some recent global opinion surveys, corruption has been identified as one of the most important problems facing the world today" (IMF - International Monetary Fund, Corruption: costs and mitigation strategies. Washington, IMF - Fiscal Affairs and Legal Departments, May 2016, p. 2).

9 Corruption and Government: causes, consequences, and reform. 2. ed. Cambridge, Cambridge University Press, 2016.

10 Conforme explica André Castro Carvalho (Direito da infraestrutura. Ed. Quartier Latin, 2014. p. 128), o problema do dimensionamento da infraestrutura no tempo acaba trazendo um risco na execução de políticas públicas nessa seara. Isso acaba sendo um campo fértil para corrupção.

11 WORLD ECONOMIC FORUM. The Global Risks Report 2016. 11. ed. Genebra, World Economic Forum, 2016. p. 9, 75. 
A corrupção afeta economias em diversos níveis de desenvolvimento, e, em alguns países desenvolvidos, a percepção da corrupção é maior do que em alguns países em desenvolvimento, o que se agrava em períodos de baixo crescimento econômico, como atesta o Fundo Monetário Internacional. É também este organismo que calcula os substanciais custos da corrupção a partir das estimativas dos subornos praticados em âmbito global - algo em torno de $\$ 1,5$ a 2 trilhôes de dólares, cerca de $2 \%$ do PIB mundial. ${ }^{12}$

E apesar da evolução que se tem experimentado no combate à corrupção em nosso país, vê-se haver ainda um longo caminho a percorrer.

A organização Transparência Internacional, dedicada a combater esse problema, criou o "Índice de Percepção da Corrupção", que tem sido aceito como indicador de corrupção nos diversos países do mundo. No índice divulgado referente ao ano de 2015, o Brasil ocupa a nada abonadora posição de número 76, de um total de 168 países [<http://www.transparency.org/cpi2015\#results-table>], e com o registro de que a situação se deteriorou no último ano, em face principalmente do escândalo envolvendo a Petrobras e da crise econômica, aumentando o desemprego e fazendo com que o povo sofra as consequências. ${ }^{13}$

A sociedade brasileira tem se mobilizado intensamente, não só individualmente como também institucionalmente. O Ministério Público Federal recentemente promoveu a campanha "Dez Medidas Contra a Corrupção", ${ }_{14}^{14}$ e até mesmo a Conferência Nacional dos Bispos do Brasil - CNBB externou grande preocupação com o tema, destacando o combate à corrupção na Campanha da Fraternidade de $2015 .{ }^{15}$

E nesse caminho o Direito Financeiro ocupa papel de destaque, por ter como objeto de estudo as normas que regulam a atividade financeira do Estado, campo em que a corrupção se mostra mais intensa e prejudicial à sociedade.

12 FUNDO MONETÁRIO INTERNACIONAL - Fiscal Affairs and Legal Department. Corruption: Costs and Mitigating Strategies. Washington, FMI. 2016. p. 4-5.

13 "Others, including Australia, Brazil, Libya, Spain and Turkey, have deteriorated. Dealing with many entrenched corruption issues, Brazil has been rocked by the Petrobras scandal, in which politicians are reported to have taken kickbacks in exchange for awarding public contracts. As the economy crunches, tens of thousands of ordinary Brazilians have lost their jobs already. They didn't make the decisions that led to the scandal. But they're the ones living with the consequences." <https://www.transparency.org/cpi2015/>.

14 <http://www.dezmedidas.mpf.mp.br/>

15 CNBB lança campanha da fraternidade com defesa do combate à corrupção. Estadão, 18 de fevereiro de 2015. 
Embora sejam múltiplos os atores e fatores envolvidos na questão da corrupção, seguramente boa parte - não seria exagero dizer, a maior parte - do combate a este mal ocorre no âmbito do Direito Financeiro, cabendo ao ordenamento jurídico estabelecer sistemas, órgãos e instrumentos de prevenção e combate à corrupção, protegendo o patrimônio público.

O sistema de fiscalização financeira e orçamentária, por meio do controle externo, a cargo do Poder Legislativo, com auxílio dos tribunais de contas, tem demonstrado há muito sua firme atuação por meio das ferramentas de fiscalização dos atos sob sua jurisdição, seja em caráter prévio, concomitante ou subsequente aos atos fiscalizados. Destaque-se a atuação dos tribunais de contas na apreciação das contas prestadas anualmente pelo Chefe do Executivo e no julgamento das contas dos administradores e demais responsáveis pela administração dos dinheiros, bens e valores públicos, do qual pode resultar a inelegibilidade daqueles que tiverem suas contas rejeitadas. $\mathrm{E}$ as atribuições são muitas, definidas na Constituição ou em outros documentos, como a apreciação da legalidade dos atos de admissão de pessoal e de concessão de aposentadorias, a fiscalização de empresas de cujo capital o poder público participe e a possibilidade de representar ao Poder competente a respeito de irregularidades e abusos apurados.

Os sistemas de controle interno têm se aperfeiçoado, especialmente após a criação da Controladoria Geral da União - CGU (hoje Ministério da Transparência, Fiscalização e Controladoria-Geral da União), cuja atuação tem sido destacada e seu modelo está se expandindo para os demais entes da federação. No Município de São Paulo, por exemplo, instituiu-se em 2013 a Controladoria Geral do Município - CGM, e logo após sua implantação foi a principal responsável pela descoberta do que acabou virando o "escândalo da máfia do ISS". ${ }^{16}$

Mesmo assim ainda há muito a avançar no campo do Direito Financeiro.

Fatos recentes com uma das empresas mais conhecidas do País, a Petrobras, mostraram que nossas empresas estatais precisam ser mais bem fiscalizadas..$^{17} \mathrm{De}$ fato, o nível de transparência e de auditoria externa das empresas estatais petrolíferas do mundo todo enfrenta dificuldades de monitoramento, um desafio dos sistemas de controle e fiscalização de diversos países. Particularmente nas empresas de capital fechado há preocupações relevantes quanto ao sigilo das informações. $\mathrm{Na}$

16 Vide coluna Controle interno mostra sua força no combate à corrupção, publicada em 19 de novembro de 2013 (e que consta neste livro).

17 Coluna Corrupção na Petrobras precisa ser apurada com rigor pelo TCU e CGU, publicada em 13 de janeiro de 2015 (e que consta neste livro). 
Petrobras, a intervenção política do período mais recente trouxe aos acionistas minoritários preocupaçôes quanto à opacidade das operações, além de provocar controles implícitos no preço da gasolina. ${ }^{18}$ Muitas outras operações e desvios trouxeram prejuízos imensos à empresa, que até hoje são sentidos em seu balanço e no valor de suas ações.

A transparência é um instrumento fundamental, cada vez mais reconhecido como um dos mais importantes para o efetivo combate à corrupção. $\mathrm{O}$ avanço nessa área tem sido significativo, mesmo assim, ainda há muito a fazer, havendo setores cujas informações guardam elevado grau de obscuridade, como foi noticiado recentemente em relação às operações do BNDES, já objeto de referência em coluna anterior. ${ }^{19}$

A conhecida frase de Lord Acton, "o poder tende a corromper; o poder absoluto corrompe de maneira absoluta", dita de forma semelhante por Rui Barbosa ("Todo o poder absoluto corrompe o homem que o possui"), mostra a importância da desconcentração de poderes, já alertada por Montesquieu ("Para que não se possa abusar do poder, é preciso que, pela disposição das coisas, o poder contenha o poder").

No âmbito das finanças públicas, isto fica evidente, e aparece com clareza na lei orçamentária, cujo processo legislativo é partilhado entre os poderes Executivo e Legislativo, mas a atribuição ao Poder Executivo do comando da execução orçamentária da maior parte da administração pública e a função de principal gestor das finanças tem se mostrado suficiente para fazer pender a balança do poder para seu lado. ${ }^{20}$ Em alguns momentos desse processo a corrupção acaba se tornando um problema, como se observa nas barganhas que ocorrem para a aprovação de emendas parlamentares à lei orçamentária, ${ }^{21}$ exigindo aperfeiçoamentos voltados a reduzir o incentivo a essa prática. E o controle sobre as transferências voluntárias torna necessário repensar a concentração de poder no ente transferidor, sem critérios claros de concessão. A falta de autonomia financeira dos municípios e de parâmetros

18 MUSACCHIO, Aldo; LAZZARINI, Sergio. Reinventando o capitalismo de Estado: o Leviatã nos Negócios - Brasil e Outros Países. Portfolio/Penguin, 2015. p. 219-225.

19 BNDES tem o dever de colaborar com a transparência dos gastos públicos, publicada em $17 \mathrm{de}$ novembro de 2015 (e que consta neste livro).

20 Como já expus na coluna Durante as eleiçôes, pense bem para quem vai entregar a chave do cofre, publicada em 26 de agosto de 2014 (e que consta neste livro).

21 Já abordadas na coluna Emendas ao orçamento e o desequilíbrio de poderes, publicada em 3 de julho de 2012, e na coluna Orçamento impositivo é avanço para a administração, publicada em 7 de maio de 2013 (ambas constam neste livro). 
mais seguros para a realização da transferência a torna um instrumento usual de barganha política em detrimento do interesse público que poderia ser atendido com o emprego criterioso desta importante ferramenta do federalismo cooperativo. ${ }^{22}$

Há instrumentos financeiros que podem em muito auxiliar no combate à corrupção, como fundos financeiros, cuja criação já foi proposta. ${ }^{23}$

Os avanços experimentados no campo do Direito Financeiro, que em muito têm colaborado para o combate à corrupção, nos permite ter hoje motivos para comemorar a Proclamação da República, com a esperança de que se continue no caminho que nos leve a um país em que a corrupção deixe de nos envergonhar perante o resto do mundo e não continue sendo motivo de preocupação.

Mas para isso há que se perseverar, pois a corrupção é "um fenômeno complexo e oportunista. Seu enfrentamento requer atitude permanente, envolvendo a adoção de medidas efetivas e simbólicas. Caso permaneçam as causas que dão ensejo à corrupção, nenhuma legislação será eficaz. ${ }^{24}$ No entanto, é pertinente ressaltar o relevante papel legislativo que o Brasil e outros países do mundo vêm desempenhando no combate legislativo à corrupção: no Brasil, o maior exemplo é a Lei Anticorrupção, de 2013. Em outros países, convém mencionar o Foreign Corrupt Practice Act (FCPA) dos Estados Unidos, o United Kingdom Bribery Act (UKBA), e o Prevention of Bribery Ordinance (POBO) de Hong Kong.

Não poderíamos, portanto, deixar passar esta data comemorativa sem ressaltar a importância deste tema para o Direito Financeiro - e que tanto desgosto nos tem dado desde o surgimento das primeiras instituições brasileiras. Por essa razão é que medidas têm de ser buscadas, por especialistas no tema e pela população em geral, para que possamos num futuro próximo comemorar o Dia da República - e livre de corrupção.

22 Vide coluna Transferências voluntárias geram desequilíbrio federativo, publicada em 28 de agosto de 2012 (e que consta neste livro).

23 LIVIANU, Roberto; CENEVIVA, Walter. Fundo contra a corrupção. Folha de S.Paulo, 2.11.2016, p. A-3: "O Instituto Não Aceito Corrupção, ao lado de diversas entidades e juristas, propôs a criação do Fundo Nacional de Combate à Corrupção (FNCC)”, que poderia financiar iniciativas de prevenção e combate a essa modalidade de crime.

24 MACIEL, Everardo. O improvável enfrentamento da corrupção. Estadão, 13 de junho de 2015. 
